\title{
Uso Endodontico do Formocresol em Permanentes Jovens. Revisão Bibliográfica.
}

\author{
$\chi$ N.F. Milano* \\ M.V.R. S $\boldsymbol{\sigma}^{\star *}$ \\ R.S. Duarte ${ }^{* *}$ \\ L.F. Torelly**
}

\section{INTRODUÇÃO}

A presente revisão bibliográfica visa trazer um pouco de luz às controvérsias que existem quanto ao emprego do FORMOCRESOL em dentes permanentes jovens. Vale salientar que o referido medicamento é o mesmo que se tem usado com alguma freqüência em pulpotomias em dentes temporários.

Este trabalho tem também por objetivo esclarecer a confusão existente entre o uso do FORMOCRESOL (Tri cresol formalina) de Buckley e o FORMOCRESOL de Berger.

Com esses fins foram consultados livros de texto e periódicos de endodontia e de odontopediatria.

Para melhor posicionamento do leitor os trabalhos foram agrupados da forma que segue:

Grupo 1 - Autores que pesquisaram o medicamento sem tomar posição quanto ao uso.

Grupo 2 - Autores ligados à endodontia favoráveis ao uso do formocresol em permanentes jovens.

Grupo 3 - Autores ligados à odontopediatria favoráveis ao uso do medicamento.

Grupo 4 - Autores ligados à endodontia que contra-indicam o uso do medicamento.

Grupo 5 - Autores ligados à odontopediatria que contra-indicam o uso do medicamento.

Grupo 6-Autores ligados à endodontia e à odontopediatria que não abordam 0 assunto.

\section{REVISÃO BIBLIOGRÁFICA}

Devido an fato dos termos Formocresol e Tricresol formalina serem empregados indistintamente, iniciaremos a revisão expondo as fórmulas do Formocresol de Berger e do Formocresol de Buckley (Tricresol formalina). Isto faz-se necessário para que fique claro que são medicamentos diferentes em suas fórmulas e em suas indicações. \section{BERGER (3)

$\begin{array}{ll}\text { Formaldeido } & 19 \% \\ \text { Cresol } & 35 \% \\ \text { Glicerina } & 15 \% \\ \text {-Água } & \end{array}$

FORMOCRESOL, de acordo com

Laboratório Crosby - Burbank Califórnia.

FORMOCRESOL, de acordo com BUCKLEY (7)

Formalina

Tricresol

partes iguais

A seguir passaremos a analisar os autores de acordo com os grupos estabelecidos.

Grupo 1

Autores que pesquisaram o medicamento sem tomar posição quanto ao uso.

Armstrong (1) realizou pulpotomias em 40 dentes permanentes jovens utilizando-se do formacresol.
Observou que a superficie imediatamente abaixo do medicamento tornou-se fibrosa e acidófila dentro de poucos minutos após a aplicação. Após 60 dias até um ano de contacto com o formocresol a polpa era fixada progressivamente até ocorrer uma fibrose da polpa inteira.

O autor comparou pulpotomias feitas com Dycal e com Formocresol em dentes permanentes jovens de macacos. Os achados indicaram a continuação do desenvolvimento radicular e fechamento do ápice. Os casos que falharam tiveram como causa bactérias encontradas dentro das polpas desses dentes.

Kleier (24) realizou estudo com 40 pacientes em tratamento endodôntico em 1: e 2: molares superiores. Em 20 pacientes foi colocado Formocresol como medicação intra canal e nos outros 20 não foi colocado nada. $O$ uso do Formocresol não alterou a dor pós-tratamento em relação ao grupo não medicado. 0 emprego do Formocresol como medicação intra canal durante 0 tratamento endodôntico de molares vitais assintomáticos não reduziu ou aumentou significativamente a dor ou sua duração quando comparada com casos sem medicação.

\footnotetext{
*Professor Titular de Endodontia da Faculdade de Odontologia da UFRGS - Porto Alegre-RS.

* *CIrurgiões Dentistas formados pela Faculdade de Odontologia da UFRGS - Porto Alegre-RS.
} 
Myers (38) estudou a absorção sistêmica do Formocresol após pulpectomias em dentes decíduos e permanentes em 5 macacos Rhesus.

Ramos (41) através de seus estudos em polpas de ratos, concluiu que as propriedades citotóxicas do Formocresol manifestam-se pela supressão da síntese do RNA, picnose ou desintegração do núcleo ou desintegração e desestabilização da membrana lisossômica.

Lazzari (27) estudou os efeitos do Formocresol sobre o tecido pulpar concluindo que este induz "cross links" de aminoácidos que transformam o tecido numa forma mais rígida e menos solúvel com marcada resistência à hidrólise enzimática tripsina e pepsina; torna o colágeno menos suscetível à digestão pela colagenase e é virtualmente sem efeito sobre carbihidratos do tecido pulpar.

Kelley (22) utilizou 20 dentes tratados com Oxpara ou com Formocresol para estudos microscópicos os quais foram feitos e comparados aos $22,85,167$ e 260 dias. Os resultados histológicos foram semelhantes devido às propriedades farmacológicas serem semelhantes dos dois medicamentos empregados.

Os molares deciduos tratados mostraram, na amostra de 22 dias, uma região de tecido pulpar fixado e bem preservado no $1 / 3$ coronário do canal; esta região misturava-se com uma zona de necrose por coagulação do tecido pulpar no 1/3 médio do canal.

Nas secções contendo 2 molares decíduos e 1 permanente, o tecido pulçar fixado foi observado invaginando-se no canal, provindo do tecido conjuntivo periapical. Necrose mais severa do tecido pulpar e mais reparação por tecido de granulação foi observada aos 85 e 167 dias nos dentes decíduos. Próximo aos 260 dias os canais estavam preenchidos completamente com tecido de granulação e foi observada ósteo-dentina forrando as paredes do canal. 01 : molar permanente apresentou padrão histológico diferente na amostra de 27 dias. Os canais estavam completamente preenchidos com tecido de granulação. Não foi observa- do tecido pulpar fixado nem necrose por coagulação. Foi observada ósteo-dentina forrando as paredes do canal. Aos 167 dias os 1 is molares permanentes apresentaram resultados histológicos idênticos aos descritos anteriormente.

As observaçōes histológicas dos 20 dentes revelaram que, 9 dentes tratados com Fermocresol e 8 dos 11 dentes tratados com Oxpara tiveram êxito. As 3 falhas no tratamento com Oxpara foram devidas às perdas das restaurações, antes dos animais terem sido sacrificados. O Oxpara ou - Formocresol podem ser usados com total eficácia como germicida e como fixador, sem causar dano permanente ao potencial reparativo do tecido conjuntivo da região periapical.

Mansukhani (33) estudou histologicamente os efeitos do Formocresol em polpas amputadas de 295 molares de ratos e 43 de dentes humanos. Nos molares de ratos não foram observadas modificações no grupo de controle aos 7 dias após a amputação. Entretanto do 14: dia em diante, a reação defensiva (fibras encapsuladas de células inflamatórias seguidas de calcificação da cápsula e formação de dentina reparativa) começou a diminuir de velocidade. Entre 21 e 28 dias a formação de dentina reparativa era menos presente em freqüência de que no grupo controle. Contudo ocorreu uma ponte pela aposição de dentina secundária ao longo das paredes laterais e à alguma distância do sítio da amputação.

Nos dentes humanos o quadro histológico foi totalmente diferente. A superficie da polpa imediatamente abaixo do Formocresol tornou-se fibrosa e acidofílica dentro de poucos minutos após a aplicação do medicamento. Depois de 7 e 14 dias a polpa mostrou três zonas distintas: uma larga zona acidofílica (fixação), uma larga zona de mancha pálida onde as células e fibras foram grandemente diminuidas (atrofia) e uma larga zona de células inflamadas encontradas na junção com a zona de mancha pálida $\theta$ difundindo profundamente no tecido pulpar normal para o ápice.

A notável diferença da reação pulpar nos molares de rato foi a ausência de tentativa de encapsular a zona inflamada. Não houve formação de dentina secundária nem reparativa evidente em algumas das espécies humanas examinadas. Aos 30 dias as zonas descritas acima tornaram-se muito largas e então a zona inflamatória foi através do ápice e a de mancha pálida foi per to do ápice. Aos 60 dias e após 1 ano a polpa foi completamente fixada e ficou com uma margem de tecido fibroso eosinofilico.

Foi muito evidente que a polpa humana não possui o potencial defensivo e reparativo que caracteriza a dos molares de ratos.

O Formocresol colocado em polpas humanas por mais de 14 dias produziu uma fixação fibrosa do tecido vivo. Para máxima eficácia como germicida e mínima ação no tecido pulpar recomenda-se que o Formocresol seja aplicado por 2 ou 3 dias e não mais de 7.

\section{Grupo 2}

Autores ligados à endodontia favoráveis ao uso do Formocresol em permanentes jovens.

Ludks $(30,31)$ comenta sobre o Formocresol como curativo de demora em casos de vitalidade pulpar, pois este possui alta tensão de vapor. Este autor também comenta que entre os fenóis aromáticos o Formocresol foi relatado como o mais efetivo, e recomenda o uso deste também em casos de necrose pulpar.

Berbert e Bramante (2) em casos de polpa viva inflamada, em que durante a pulpotomia o sangramento foi deficiente ou vermelho escuro ou ainda advindo de remanescentes pulpares sem textura, optam pela colocação de uma bolinha de algodão embebida, sem excesso, em Formocresol e selado com $\mathrm{ZnO}$ + Eugenol, como tratamento de urgência o que resolveria o problema da dor até que fosse feita a pulpectomia.

Ingle e Beveridge (20) recomendam que o Formocresol pode ser usado nas seguintes situações: sempre que um trajeto fistuloso esteja presente na região periapical ou através dos espaços periodontais; quando uma drenagem excessiva 
ocorre nas visitas posteriores à primeira consulta; quando persiste por dias após uma consulta ou quando a manipulação completa do canal não foi bem sucedida. Os autores referem haver evidências clínicas de que as fistulas fecham mais rapidamente e que os canais com drenagem excessiva ressecam mui to mais cedo do que com o uso de outros medicamentos.

Para Lasala (26) os antissépticos contendo Formocresol são empregados em duas indicações precisas: quando ao trabalhar na segunda sessão ou nas seguintes, 0 1/3 apical estiver doloroso, talvez por haver restado polpa residual, ou quando, após exaustivos esforços não se conseguir preparar o canal em toda a sua extensão.

\section{Grupo 3}

Autores ligados à odontopediatria favoráveis ao uso do medicamento.

Myers (37) realizou estudo clínico tratando 66 molares permanentes despolpados com Formocresol como medicação intra-canal. Em $85 \%$ dos casos notou-se eliminação ou redução da rarefação apical inicial; em $4,5 \%$ não houve modificação no aspecto radiográfico; em $10,6 \%$ houve aumento na rarefação apical. Todos os dentes mostraram a continuação da apicificação e aumento no tamanho da raiz.

Fiskio (15) estudou 148 dentes permanentes tratados com Formocresol constatando que $91 \%$ não necessitavam tratamento adicional.

Kennedy (23) observou que quando um dente vital ou desvitalizado com ápices abertos ou fechados, deve ser mantido a curto prazo a espera de tratamento endodôntico ativo, pode ser obtido êxito realizando-se uma pulpotomia com Formocresol.

Trask (46) corrobora com Kennedy dizendo que a técnica é semeIhante à usada para dentes temporários, sendo a sensibilidade pós-operatória em dentes vitais controlada com aspirina.

Muniz $(35,36)$ realizou trabalho investigando pulpotomias com Formocresol em dentes permanentes uni e multirradiculares, com polpa viva ou necrótica. Consider ou-as exitosas quando não havia sintomas clíni$\cos e$, ao exame radiográfico era observado reparação apical e diminuição da luz do conduto. Os sintomas de complicação periapical como edema, fistula, etc., desapareciam geralmente antes de 30 dias $e$, aos 6 meses, o autor observou sinais evidentes de reparação tecidual periapical. $O$ autor relata que a resposta tecidual observada neste trabalho, no conduto radicular dos dentes permanentes jovens, vêm a colaborar para a hipótese da presença de novo tecido de origem conjuntiva e fibrosa no conduto, bem como a calcificação das paredes deste com dentina amorfa. Segundo o autor, se uma lesão é irreversível e um processo de mortificação pulpar começa a se instalar, o organismo poderia, desde que não houvesse infecção nesse conduto, realizar uma reparação do tipo cicatricial, cujo mecanismo aparente baseia-se na invaginação do periodonto, substituição do conteúdo do conduto por tecido conjuntivo e calcificação de grande parte da luz do conduto. O novo tecido conjuntivo é fibroso, com escassas células, pouco vascularizado e inervado e não inflamado. $O$ tecido calcificado é do tipo dentina amorfa.

Para Trask (45), dentes permanentes com polpas necrosadas podem ser tratados com sucesso pelo mesmo procedimento usado para molares decíduos, ou seja, uma pulpotomia em duas etapas, com uso do Formocresol. Este tratamento pode ser usado como uma alternativa à exodontia, todavia o tratamento endodôntico completo deve ser realizado posteriormente. Em seu estudo foram tratados 43 pacientes com idades entre 08 e 23 anos e os dentes tratados foram sempre 1: e 2: molares permanentes. Os dentes apresentavam sinais e sintomas de degeneração pulpar, alguns possuindo tractos fistulosos, radiolucidez periapical e mobilidade. Foram realizadas as pulpotomias sob isolamento absoluto com a aplicação do Formocresol (solução de Buckley) com bolinha de algodão diretamente sobre os cotos pulpares por 5 minutos.
Ao final removia-se a bolinha de algodão com Formocresol e sobre os cotos pulpares colocava-se outra; sobre esta colocava-se óxido de zindo e eugenol, podendo-se restaurar na mesma sessão, tirando-se o dente de oclusão.

\section{Grupo 4}

Autores ligados à endodontia que contra-indicam o uso do medicamento.

Coolidge (11) analisando a reação dos tecidos periapicais ao Formocresol como medicação intra-canal, após a remoção de polpa vital de cães, por 21 dias, verificou que - Formocresol produzia em grau diferente, reação inflamatória moderada e necrose dos tecidos vizinhos.

Cohen (10) comentando sobre 0 uso do Formocresol como curativo de demora em necrose pulpar, alerta quanto ao seu poder irritante.

Segundo Grossman (16), o Formocresol é um desinfetante potente que não só tende a irritar como também a destruir e fixar tecido; o Formocresol causa notáveis irritações e necroses.

Sommer (43) opina que soluções de aldeido-cresol-formol são muito cáusticas para serem seladas em canais radiculares.

A concentração de $1 / 5$ de Formocresol é tão eficaz na fixação tecidual quanto a concentração total. Estes estudos feitos por Loos e Han (29) indicam o efeito altamente irritante da preparação atualmente usada; mesmo sendo empregado na forma mais diluída, o Formocresol ainda causa a fixação do tecido.

A experiência clínica de Filgueiras (13) mostrou que o Formocresol, especialmente quando encerrado no $1 / 3$ apical dos canais, é irritante, razão pela qual caiu em desuso.

Em trabalho realizado por Wemes (48), foram tratados canais de 12 pares de incisivos humanos, sem patologia óssea ou periapical, com Formocresol e Glutaraldeído. $\mathrm{O}$ curativo sempre resultou em irritação dos tecidos periapicais.

Segundo Valdrighi (48), o Formocresol possui efeitos citotóxicos severos, o que impede seu uso como medicação intra-canal. 
Seltzer e Bender (42) não recomendam o uso desse medicamento em polpas de dentes permanentes.

As pulpotomias com Formocresol realizadas por Block (4) causaram os seguintes efeitos:

1. Necrose por coagulação indicada por perturbações circulatórias, inflamação aguda e crônica, reabsorção e aposição.

2. Lesão periapical indicada por uma inflamação aguda e crônica, reabsorção radicular e óssea e aposição.

3. Uma resposta generalizada indicada pela presença e paraformaldeldo marcado com "C" no sangue, nódulos linfáticos regionais, rins e figado. O Formocresol não deveria ser colocado em contacto com tecido humano.

Em experiência clínica realizada por Block (5), foram tiradas as seguintes conclusões: quando incuba-se Formocresol em tecido pulpar de cão este tecido torna-se antigenamente ativo. Obteve-se uma resposta da proliferação linfocitária imune mediada por células em relação a um tecido pulpar alterado por Formocresol. O canal radicular é um modo efetivo de imunização.

Para Morse (34) o Formocresol não é recomendado para dentes permanentes por seus efeitos deletérios a longo prazo.

\section{Grupo 5}

Autores ligados à odontopediatria que contra-indicam o uso do medicamento.

Segundo Finn (14) o Formocresol era considerado desinfetante para canais em tratamento endodôntico de permanentes. Ainda que muitos clínicos apoiassem a sua utilização durante anos, 0 uso desse medicamento não foi respaldado por estudos histológicos convincentes até à última década. Atualmente tem sido investigada a ação dessa droga em polpas vivas de dentes de ratos, macacos e peças humanas.

$A$ indicação da pulpotomia com Formocresol é cabivel somente em dentes decíduos já que não existem estudos científicos de natureza clinica e histológica sobre a ação do
Formocresol em dentes permanentes.

Nishino (39) acredita ser um engano extrapolar-se o sucesso da pulpotomia com Formocresol em dentes deciduos para dente permanentes, argumentando que os dentes decíduos, pelo fato de se esfoliarem mais cedo, raramente apresentam inflamações agudas e crónicas decorrentes do uso do Formocresol. Os dentes permanentes, por outro lado, proporcionariam um potencial para futuras infecções ou inflamações periapicais, mormente por causa de sua duração na arcada e assim, expostos às condições patológicas.

\section{Grupo 6}

Autores de endodontia e odontopediatria que não abordam o assunto.

Holland (19), Issáo e Pinto (21), Valdrighi (47), De Deus (12), Harndt (17), Hogeboom (18), Kuttler (25), Maisto (32), Ostby (40), não se ocupam do uso do Formocresol em permanentes jovens.

Buckley (8), Tancredo (44), Leonardo (28), recomendam seu uso, todavia, de acordo com a primitiva idéia de Buckley, somente para a neutralização do conteúdo necrótico do canal, devendo ser colocado na entrada da câmara pulpar nos casos de gangrena putrescente, sempre antes da instrumentação do canal.

\section{RESUMO E DISCUSSÃO}

Este capítulo será desenvolvido em função dos grupos de autoresestudados.

\section{Grupo 1}

Autores que pesquisaram o medicamento sem tomar posicionamento.

Neste grupo notou-se uma considerável diversidade de abordagens do tema, o que tornou diffcil um apanhado global.

Há trabalhos em animais e humanos com manifesta discrepância de resultados. 0 medicamento foi empregado, em alguns casos na câmara pulpar e em outros de forma intra- canal, dificultando a interpretação dos resultados.

Os fenômenos histológicos observados são variados, deixando como idéia comum a fixação de tecidos sob a ação do Formocresol e eventual penetração de tecido conjuntivo através do forame.

Em resumo, em função da variação no material e método de trabaIho utilizados não foi viável resumirse o mecanismo de ação do medicamento nas diferentes situaçōes de uso.

\section{Grupo 2}

Autores de endodontia favoráveis ao uso do medicamento.

A leitura deixou ver uma grande pluralidade de enfoques, especialmente na indicação e modo de utilização do medicamento, não ensejando dessar te, uma apreciação favorável ou desfavorável do Formocresol. Parece clara a mistura de idéias no que respeita ao pensamento de Buckley ou de Berger a respeito do Formocresol.

\section{Grupo 3}

Autores de odontopediatria favoráveis ao uso do medicamento.

Este grupo de autores recomenda o uso do Formocresol para polpas vivas ou necróticas, com forames completos ou abertos.

Dado o grande espectro de abordagens é fácil observar-se que o medicamento tem farta utilização em odontopediatria.

\section{Grupo 4}

Autores ligados à endodontia contrários ao uso do medicamento.

Os autores situados neste grupo asseveram o poder irritante do Formocresol, contra-indicando seu uso em endodontia.

\section{Grupo 5}

Autores de odontopediatria contrários ao uso do medicamento.

Os trabalhos deste grupo posici onam-se contra o emprego do Formocresol em permanentes jovens assegurando que o que ocorre em dentes temporários não têm de ocorrer necessariamente em permanentes. 


\section{Grupo 6}

Finalmente neste grupo situa-se um número considerável de autores de renome que se omite de citar a utilização do Formocresol em endodontia de permanentes joens.

\section{COMENTÁRIO FINAL}

Observando-se tudo o que foi dito em uma visão panorâmica é fácil concluir-se a grande variedade de enfoques que é dado ao uso do Formocresol.

Tudo começou com Buckley que recomendou o Formocresol ou Tricresol formalina em partes iguais, para a transformação dos produtos da decomposição do tecido pulpar quando de uma gangrena da polpa (necrose putrescente).

Posteriormente Berger, modificando a fórmula do Formocresol, lança seu emprego em odontopediatria. Estranhamente, em nosso entender, o mesmo produ to é recomendado para polpas vivas e necróticas, na câmara pulpar ou intra-canal. Variável é também a permanência do medicamento.

Mais atualmente surgiram as incursões no emprego em permanentes jovens ou adultos.

Como este último enfoque foi a razão primordial desta revisão bibliográfica, cremos ser válido poder pensar-se que, dada a falta de embasamento cientifico, pelo menos por enquanto, não vemos viabilidade de indic ação do Formocresol em dentes permanentes, a menos que sejam adotadas as primitivas idéias de Buckley, que nada têm a ver com o uso do dito medicamento em odontopediatria.

\section{REFERÊNCIA \\ BIBLIOGRÁFICA}

1. ARMSTRONG, R.L. et alii. - Comparision of dycal and formocresol pulpotomies in young permanent teeth in monkeys. Oral Surgery, Oral Patology, Oral Medicine, 48(2):160-8, Aug, 1979.

2. BERBERT, Alceu \& BRAMANTE, Clovis M. - Tratamentos endodónticos de urgência. Revista Brasileira de Odontologia, 33(4):258-71, 1976.
3. BERGER, J.E. - Pulp tissue reaction to formocresol and zinc oxide-eugenol. $J$. Dent Child, 32:13-28, 1965.

4. BLOCK, R.M. et alii. - Sistemic distribuition of $14 \mathrm{C}$ Labeled Para-Formaldeyde incorporated within formocresol following pulpotomies in dogs. Journal of Endodontics, 9(5):176-89, May, 1983.

5. BLOCK, R.M. et alii. - Cell mediated immune response to dog pulp tissue altered by formocresol within the root canal. Journal of Endodontics, 3(11):424-29, Nov, 1977.

6. BRAUER, J.C. - Odontologia para nĩnos. 2.ed. Buenos Aires, Mundi, 1955.

7. BUCKLEY, J.P. - Matéria médica, farmacologia e terapêutica dentárias. Rio de Janeiro, Scientifica, 1945. p.357.

8. BUCKLEY, J.P. - Sterilization of infected root canals. Apud GROSSMAN, Lol. Journal of the American Dental Association, 85(4):900-5, Oct, 1972.

9. COHEN, M.M. - Odontologia pediátrica. Buenos Aires, Mundi, 1958. Trad. de Samuel Leyt.

10. COHEN, S. \& BURNS, R.C. - Microbiology and pharmacology. In:_. Pathways of the pulp. Saint Louis, Mosby, 1976. Cap. 11, p.324.

11. COOLIDGE, E.D. - Tratamento conservador da polpa viva. Capeamento. Apud PAIVA, J.G. \& ANTONIAZZI, J.H. Endodontia, bases para a prática clínica. Artes Médicas, 1984. p.448.

12. DE DEUS, Q.D. - Endodontia. 3.ed. Rio de Janeiro, Medsi, 1982.

13. FILGUEIRAS, et alii. - Endodontia Clínica. Rio de Janeiro, Científica, 1962. p.255 e 272.

14. FINN, S.B. - Tratamiento pulpar de piezas primárias. In:__. Odontologia pediátrica. 4.ed. Interamericana, 1976. p.189-91. Trad. de Carmen Munoz Seca.

15. FISKIO, H.N. apud INGLE J.l. e BEVERIDGE, E.E. - Endodontia. 2.ed. Rio de Janeiro, Interamericana, 1976. p.698. Trad. de José Carlos Borges Teles.

16. GROSSMAN, L.I. - Sterilization of infected root canals. Journal of the American Dental Assaciation. 85(4):900-6, Oct, 1972.

17. HARNDT, $E_{0}$ \& WEYERS, $H_{0}$ - Odontologia pediátrica. Buenos Aires, Mundi, 1969.

18. HOGEBOOM, F.E. - Odontologia infantil e higiene odontologica. 6.ed, México, 1958.

19. HOLLAND, R. et alii. - Endodontia. Aracatuba, s.ed. 1972.

20. INGLE, Jal. \& BEVERIDGE, E.E. - Endodontia. 22d. Rio de Janeiro, Interamericana, 1976. Trad. de José Carlos Borges Teles.

21. ISSÃO, M. \& PINTO, A.C.G. - Manual de odontopediatria. 6.ed. Artes Médicas, 1984.

22. KELLEY, M_A. et alii. - Histologic evaluation of formocresol and oxpara pulpotomies in Rhesus Monkeys. Journal of the American Dental Association. 86(1):123-27, January 1973.

23. KENNEDY, D.B. - Tratamiento pulpar, técnicas de tratamiento. Operatória dental en pediatria. Buenos Aires, Panamericana, 1977. p.234-51.

24. KLEIER, D.J. \& MULLANEY, T.P. - Effects of formocresol on post treatment pain of endodontic origin in vital molars. Journal of Endodontics. 6(5):566-9, May, 1980.

25. KUTLER, Yuri - Endodontia prática. México, Ed. Alpha, 1961.

26. LASALA, A. - Pulpectomia total. In:__Endodontia. 2.ed. 1971. Cap. 18. p.420-7.

27. LAZZARI, E.P. et alii. - Biochemical effects of formocresol on bovine pulp tissue. Oral Surgery, Oral pathology, Oral Medicine. 45(5):769-802, May, 1978.

28. LEONARDO, M. et alii. - Fase de desinfecção de canais radiculares. In:

Endodontia, tratamento de canais radiculares. São Paulo, Panamericana. Cap. 16. P.242.

29. LOOS, P.J. \& HAN, S.S. - Sterilization of infected root canals. Apud GROSSMAN, L.I. Journal of the American Dental Association. 85(4):900-5, Oct, 1972.

30. LUCKS, S. - Conservative treatment of non vital teeth. In:___. Pratical endo dontics. Philadelphia, J.B. Lippincott Company, 1974. Cap. 10. p.94.

31. LUCKS, S. - Treatment of vital teeth. In:_. Pratical Endodontics. Philadelphia. J.B. Lippincott Company, 1974. Cap. 9. p.86.

32. MAISTO, O. Endodoncia. Buenos Aires, Mundi, 1967.

33. MANSUKHANI, N. \& MASSLER, M. Effects of formocresol on the dental pulp. Journal of dentistry for children. 125(4):277-96, May, 1959.

34. MORSE, D.R. - Treatment planning. In:_. Clinical endodontology. Springfield, Charles C. Thomas, 1974. Cap. 3. p.307.

35. MUNIZ, M.A. - La técnica del formocresol en permanentes jóvenes. Revista de la As sociacion Odontologica Argentina. 67(3):123-36, Buenos Aires, May, 1979.

36. MUNIZ, M॰A. et alii. - La técnica del formocresol en dientes primários. Estudo histołógico de casos pós tratamientos proJongados. Revista de la Associacion Odontologica Argentina, Buenos Aires, $70(4): 229-33$, Jun. 1982.

37. MYERS, D.R. apud INGLE, J.I. e BEVERIDGE, E.E. - Endodontia. 2.ed. Rio de Janeiro, Interamericana, 1976. p.698-700. Trad. de José Carlos Borges Teles.

38. MYERS, D.R. et alii. - Distribuition of 14C formaldehyde after pulpotomy with formocresol. Journal of the American Den. tal Association. 96(5):805-13, May, 1978.

39. NISHINO, PK. apud INGLE, J.l. e BEVERIDGE, E.E. - Endodontia. 2.ed. Rio de Janeiro, Interamericana, 1976. p.698-700. Trad. de José C. Borges Teles.

40. NIGARD-OSTBY, Birger - Introductions to endodontics. Oslo, Scandinavian Univ. Books; Universitet Foriaget, 1971.

41. RAMOS, D.L et alii. - The effects of formocresol and glutaraldehyde on rat pulp respiration. Journal of dentistry for chil- 
dren. 47(2):38-41, March-April, 1980.

42. SELTZER, S. \& BENDER, J.B. - Capeamento pulpar e pulpotomia. In: . A polpa dental. 2.ed. Rio de Janeiro, Editora Labor do Brasil, 1973. Cap. 14. p.368-9.

43. SOMMER, R.F. et alii. - Clinical endodontics. 2.ed. Philadelphia W.B. Saunders, 1961. p.215 e 569 .

44. TANCREDO, N. et alii. - Medicação intracanal. In: - Manual de endodontia. Rio de Janeiro, Guanabara Koogan, 1980. p.202-3.

45. TRASK, P. - Formocresol pulpotomy on young permanent teeth. Journal of the American Dental Association, 85(6):1316-23, Dec, 1972.

46. TRASK, P. apud KENNEDY, D.B. - Operatória Dental en pediatria. Buenos Aires, Panamericana, 1977. Trad. de Irma Lorenzo.

47. VALDRIGHI, L \& HIZATUGU, R. - Endodontia, consideraçöes biologia e aplicaçöes clínicas. Piracicaba, Aloisi Ed., 1974.

48. VALDRIGHI, L. et alii. - Estudo comparativo da atividade antimicrobiana do pmcc, do iodeto de potássio iodetado a 2 e do formocresol. Revista Paulista de Endodontia. 3(3):51-6, 1982.

49. WEMWS, J.C. et ali, - Histologic evaluation of the effect of formocresol and glutaraldehyde on the periapical tissues after endodontic treatment. Oral Surgery, Oral Patology, Oral Medicine. 54(3):329-32, Sep, 1982. 